\title{
FINAL DEGREE PROJECTS AS A TOOL FOR INNOVATION AND ENTREPRENEURSHIP
}

\author{
L. Hojas Hojas, E.M. García del Toro \\ ETS Ingeniería Civil. Universidad Politécnica de Madrid (SPAIN)
}

\begin{abstract}
The training offer that the Spanish educational system presents today, especially university training, does not meet, in many cases, the expectations demanded by today's society.

The education system is sometimes too rigid, even outdated in some respects. These are the main causes that make study plans need constant updates. The procedure for modifying these plans is sometimes slow and laborious. For this reason, the adaptation of existing training elements is considered one of the best options to incorporate new skills without the need to modify the study plans. Highlighting within these, the Final Degree Projects (TFG).
\end{abstract}

Therefore, the Final Degree Project is considered one of the most flexible tools that university education currently has to introduce new skills that a modern society demands of its graduates. Among which are: creativity, innovation, criticality, collaboration and communication.

In this context, the Educational Innovation Project: "Design and Participation in Engineering", approved by the Universidad Politecnica de Madrid (IE1929.5803), is presented in this communication, where the need to effectively apply the tools that the University makes available to students to implement the TRL (Technology readiness levels) methodology and Desing Thinking procedures, applied to TFG's.

The objectives of this project are:

- Facilitate and enhance collaboration between students of the Civil Engineering and Industrial Design Schools of the Universidad Politécnica de Madrid, in the preparation of Final Degree Project.

- Integrate the creativity of the authors of the projects with their diffusion and social propagation.

The TFG's that are part of this Educational Innovation Project, and that will take place throughout this academic year, are oriented towards collaboration, where the students of the School of Civil Engineers provide updated knowledge and adapt new needs for the design of Civil Engineering and Territorial Planning infrastructures and the students of the School of Engineering and Industrial Design leading industrial technologies to improve efficient monitoring and control systems as well as the sustainability of infrastructures.

Keywords: Educational Innovation, Final Degree Project, Technology readiness levels, Desing Thinking, Collaborative Works.

\section{INTRODUCTION}

Modern societies demand well-trained professionals who participate in the processes of research, innovation and development at the highest level [1]. They also need citizens capable of managing and participating in a world in which science-based decisions are an everyday part of life. The university plays a decisive role in this training and must adapt to what society expects of its graduates [2].

Engineering education since its inception has been conditioned by different changes that have made it evolve while enriching [3]. Throughout history, it has been a common concern for universities to provide training to students in accordance with the needs of the environment in which they live and operate [4].

In order to achieve this purpose, it is necessary for the professional training to overcome the paradigm in which the acquisition and transmission of knowledge predominated and to assume a new one oriented to generate new forms of thought and action, more appropriate to the characteristics of the new times, which allow training professionals who are capable of continuous or permanent learning [5]. 
In this sense, engineering education demands certain needs to ensure that the training process meets the demands of the context.[6]. This aspect requires an organization of the educational teaching process cantered on the student, developed in an interactive and collaborative way and that allows him to acquire valid learning to face the challenges that he will have to overcome in his professional life.[7].

The education system is sometimes too rigid, even outdated in some respects. These are the main causes that make study plans need constant updates. The procedure for modifying these plans is sometimes slow and laborious. For this reason, the adaptation of the existing training elements is considered one of the best options to incorporate new skills without the need to modify the study plans. Highlighting within these, the Final Degree Projects (TFG).

In this context, the Educational Innovation Project: "Design and Participation in Engineering", approved by the Polytechnic University of Madrid (IE1929.5803), is presented in this communication. Such project is aimed at fostering entrepreneurship and collaboration between students from two engineering schools in order to effectively apply the tools that the university makes available to students to implement the TRL (Technology readiness levels) methodology and the Desing procedures. Thinking, applied to TFG's.

The work we present is based on the idea that an end-of-degree project is not a document made only to be qualified by an evaluation court, but rather it must be a work that presents a practical application and that provides a real solution to a lawsuit raised by society[8].

Projects must be planned looking for long-term results. In addition, whether they are entrepreneurship projects or the visualization of a technology, they must be aimed at being carried out, or at least at showing the skills and abilities that the students have attained in their university studies.[8].

In the Educational Innovation Project that we present here, the final degree projects that it comprises are multidisciplinary and need different specialties that work together to design different alternatives and among them choose the one that best adapts to the characteristics of the problem that is intended sort out.

The collaboration between the disciplines of Civil Engineering and Engineering and Industrial Design is considered as a promising cooperation in the development of solutions linked to mobility and land management

The transformation of mobility, new infrastructure control and management systems, environmental monitoring and control, and the use of emerging technologies to develop new solutions are the objectives that we seek in the final degree projects that we propose in the project.

To achieve these objectives, these lines of action have been proposed:

1 Improve students' adaptation to the working market

2 Introduce the participation of external agents in the design process

3 Favouring entrepreneurship through solutions-oriented projects applicable in today's market

4 Encourage collaboration and networking

\subsection{Improve student adaptation to the working market}

A high unemployment is observed in the civil engineering sector. The production and consumption of cement since its peak in 2007 has been reduced by approximately $60 \%$. Therefore, it is necessary to reorient the professionals dedicated to this sector. Professionals more prepared for the introduction of ICT-oriented systems and the adaptation of existing infrastructures to the needs of the next 20 years are needed. A clear example is the automation of mobility systems, which requires the adaptation of roads with all kinds of sensors and automatisms and a deep knowledge of the tools that allow their exploitation.[9]

\subsection{Introduce the participation of external agents in the design process.}

Another important factor in carrying out the work is to introduce rational solution design processes. For this, the aim is to promote the participation of social agents in the proposal of solutions linked to infrastructures, and in general to Civil Engineering. To get it, the Design Thinking methodology is proposed. 


\subsection{Encourage entrepreneurship through solutions-oriented projects applicable to the current market}

To achieve this, students are oriented to present solutions that can be developed in the entrepreneurial environment that the Polytechnic University of Madrid is advocating. The reference is the ActúaUPM programs developed by the University [10]. The objective is for students to become aware of the need to find mechanisms for the dissemination and financing of projects. Participating in an entrepreneurship program is a very effective way for students to be aware, on the one hand, of the competition that exists in society and, on the other, of the need to communicate solutions to nonspecialists in the field of work [8]

\subsection{Promote collaboration and networking}

Collaboration between students for the development of their final degree projects is a means to encourage the creation of professional work networks. In 21 st century society, working is collaborating with other people to carry out a project.

\section{METHODOLOGY}

The first step is to select the final degree projects that will be part of the Educational Innovation Project. This selection is carried out in two phases:

1 Phase 1: Dissemination of different activities

2 Phase 2: Selection of projects and creation of working groups

The dissemination of activities has been carried out through the organization of discussion workshops with presentations, organized in TED mode, by the tutors. The topics proposed for the talks have been the following:

- Vehicle Motorization

- Autonomous Driving

- Hyper light Transport

- The Drones revolution

- Mobile Engineering

- Environmental Monitoring

- Artificial Intelligence and Deep Learning in Engineering

An example of the type of dissemination, that will be done among students, to increase interest in these topics the posters in figure 1 are designed:
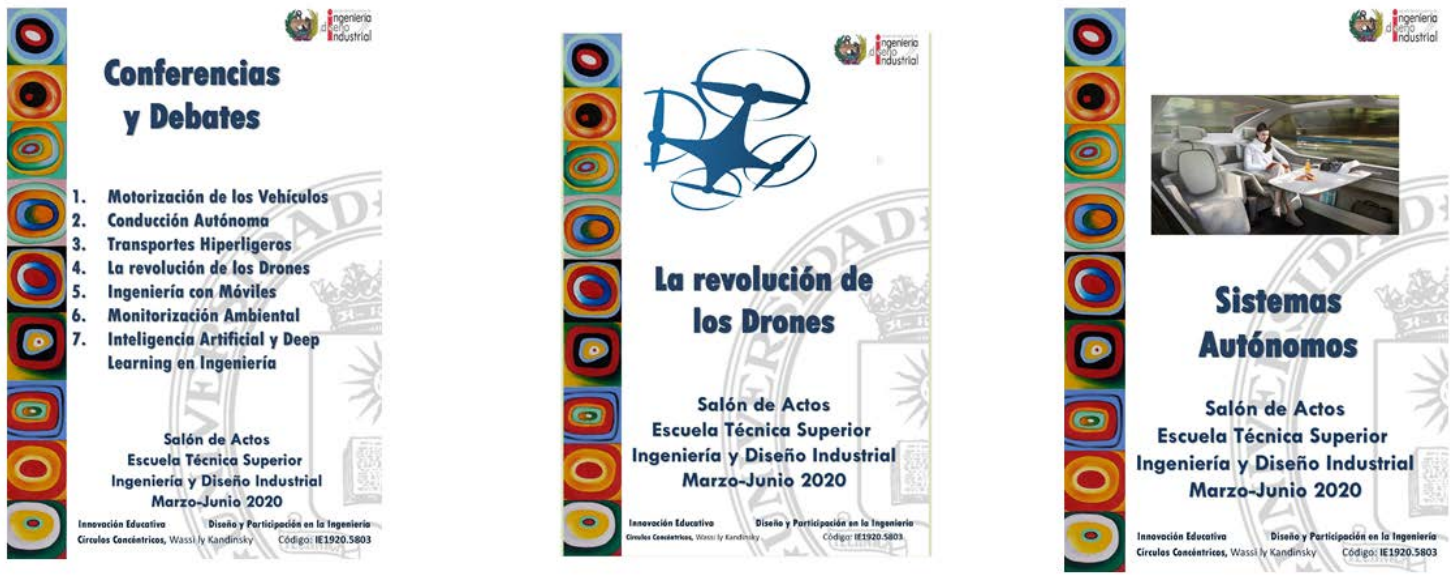

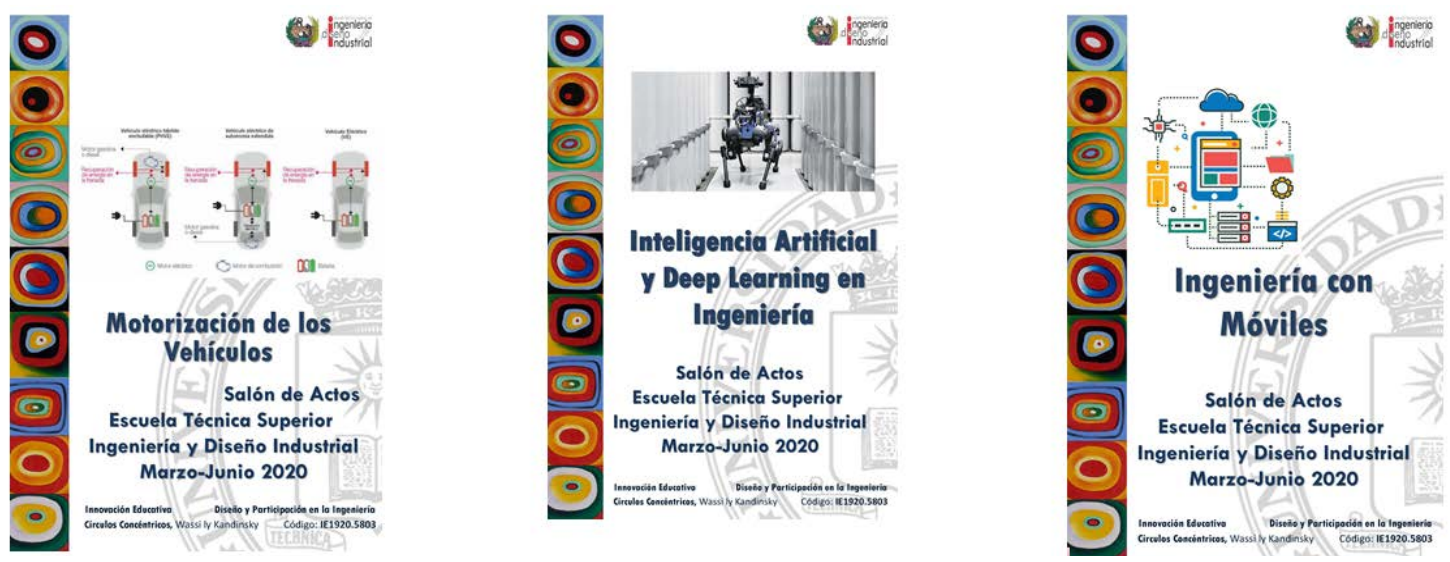

Figure 1. Posters to encourage student participation in organized talks.

In the second phase the student groups will be selected, which will be made up of ten members per center. Ten projects will be developed that will have to be carried out jointly by two students, one from the ETS Civil Engineering and the other from the ETS of Industrial Design. The student of the ETS of Civil Engineering will carry out the part corresponding to the design of the civil works, while the student of the ETS of Industrial Design will carry out the tasks corresponding to the industrial engineering of the projects. The works will be carried out jointly and with a common methodology, although they will be graded individually. Each student will present in their corresponding school the part they have done and will be qualified by it, to follow the academic regulations in this regard.

In order to standardize the criteria for both the preparation of work by students and their evaluation by teachers, two work methodologies are proposed: TRLE (Technology Readiness Levels)[11] and Design Thinking [12].

\subsection{TRLE Methodology}

Figure 2 shows a diagram of the different phases that make up the working technique.

\section{TECHNOLOGY READINESS LEVELS - TRL}

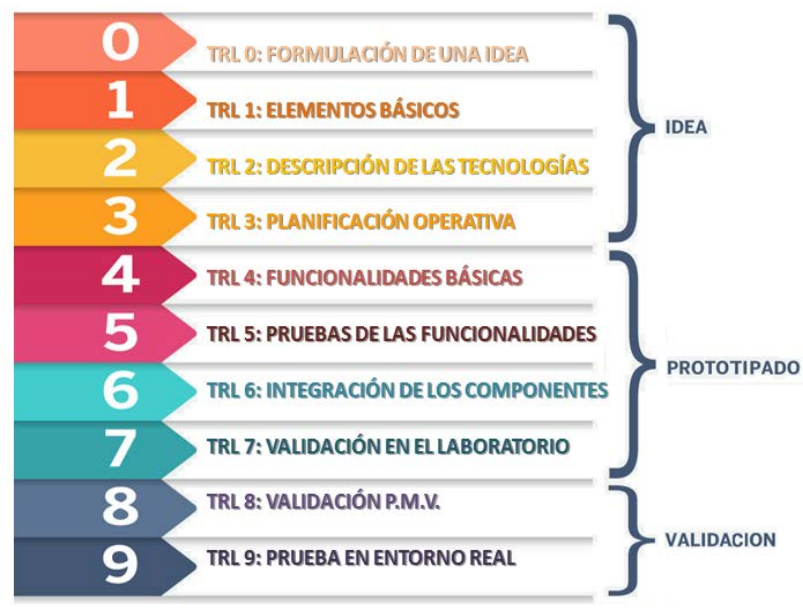

Figure 2. Outline of the TRL Methodology (adapted by the authors to the GFRs)

The realization of the projects is divided into 3 blocks:

- Idea

- Prototyping

- Validation 


\subsubsection{Idea}

It covers the following phases:

- TRL 0: formulation of an idea

- TRL 1: basic elements

- TRL 2: description of technologies

- TRL 3: operational planning

TRL 0. Formulation of an idea

The formulation is a very short text with the objectives of the project

$\underline{\text { TRL 1. Basic elements }}$

The basic elements describe the most important characteristics of the project, specifying the objectives in a practical way, the users, the advantages that it will provide to users, the competition that exists in the market and a first approach to the technologies involved in the project.

TRL 2. Description of the technologies

Detailed description of the technologies that are intended to be used, describing their characteristics, companies that provide this equipment, acquisition and maintenance costs and, in general, practical information for their implementation.

\section{TRL 3: Operational planning}

Operational planning is a work schedule with control milestones that can be verified by an external agent. It has a double objective, on the one hand it serves to control that the established objectives are being met and on the other it is a mechanism to review the work schedule.

\subsubsection{Prototyped}

The second block is the development of a prototype. Depending on the type of project, the objectives of the different activities may change, adapting to the needs of the project. This block has the following phases:

- TRL 4: Basic functionalities

- TRL 5: Testing functionality

- TRL 6: Integration of components

- TRL 7: Validation in the laboratory

\section{TRL 4: Basic Funcionalities}

The basic functionalities consist of the description of the operating blocks that the system will have. Elements must be built that can be validated independently to facilitate the management of problems and errors in the later phases of the system.

TRL 5: Testing functionality

The blocks must be verified one by one. Trying to look for problems that may occur in the testing phase of the systems as a whole.

TRL 7: Validation in the laboratory

Practical operation of the laboratory systems, taking data on the different factors that may intervene, such as energy consumption, error rate, system blocking, etc.

\subsubsection{Validation}

Finally, the validation of the system by teams external to the work group that verify that the results are those expected in the system. It comprises two stages:

- TRL 8: validation MVP (Minimum Viable Product)

- TRL 9: test in real environment 


\section{TRL 8: Validation PMV}

In this phase, the operation of this system is checked so that it can be verified by agents outside the working group.

\section{TRL 9: test in real environment}

In this last phase, the operation in a real environment is verified, and there should also be the presence of external agents to the work group

\subsection{Design Thinking}

It is a methodology that has tools aimed at participation and very useful in applying to "Smart Infrastructures", "Smart Cities" ... etc. It has the following phases:

- Discovery

- Interpreration

- Ideation

- Experimentarion

- Evolution

\subsubsection{Discovery}

This first phase consists of posing a challenge, analyzing problems and difficulties, proposing solutions and then planning activities to achieve the result.

\subsubsection{Interpretation}

In this stage, significant information is gathered from all points of view that are involved in the project. The data to be taken are raised, the technical problems that may occur and the acceptance of society (users and administration) towards the project that will be disclosed through the processes of participating. For this it is important to generate an open debate between the parties involved in the project.

\subsubsection{Ideation}

It consists of determining which is the most relevant solution and developing the technical means to carry it out.

\subsubsection{Experimentation}

It is necessary to develop a prototype, as simple as possible to develop the operational characteristics that the proposed solution would have. This prototype is called the Minimum Viable Product.

\subsubsection{Evolution}

Finally this product will lead to a document that in our case will be the Final Degree Project.

Once the projects have been completed, the last training activity that is proposed is the possibility that the best projects presented can participate in the ACTÚA UPM plan[10] that rewards the best projects aimed at promoting entrepreneurship and business creation among UPM students and professors

\section{RESULTS}

As a consequence of the suspension of face-to-face academic activity due to the pandemic caused by COVID19, we still do not have academic results of the Educational Innovation Project that we expose in this work. But from the teacher's point of view we believe that with the proposed methodologies the objectives set out in the project will be met, especially the promotion of collaboration between different disciplines in order to successfully face a Final Degree Project, mainly those aimed at entrepreneurship and technical innovation 


\section{CONCLUSIONS}

With this Educational Innovation Project: "Design and Participation in Engineering", approved by the Polytechnic University of Madrid (IE1929.5803), the aim is to effectively apply the tools that the university makes available to students to implement the TRL methodology ( Technology readiness levels) and Desing Thinking procedures, applied to TFG's.

By applying these technologies, the aim is to encourage the development of certain techniques related to the preparation of final degree projects, among which the following stand out:

- More agile and flexible Work Techniques

- Collaboration between Centers to develop newer projects

- Collaboration between Students with different training to find solutions

- Promotion of Social Participation in the design process

- Promotion of entrepreneurship activities

- Create Interdisciplinary Work Networks

These techniques will affect the completion of some final degree projects, aimed at obtaining graduates with training more in line with the needs of the environment in which they live and operate

\section{REFERENCES}

[1] F. M. Martínez, "El proceso de inserción laboral: Implicaciones educativas para mejorar la empleabilidad.," Rev. Complut. Educ., vol. 20, no. 2, pp. 455-471, 2009.

[2] D. Q. Naguyen, "The essential skills and atributes of Engineering: A comparative Study of Academic Industry Personnel and Enginerring Students.," Glob. J. Eng. Educ., vol. 2, pp. 65-76, 1998.

[3] Z. D. Zhang Y., Bai L., "Strengthening the Engineer's Lifelong Education.," Adv. Mater. Res., vol. 156-157, pp. 241-244., 2011.

[4] D. Azevedo, A., Apfelthaler, G., y Hurst, "Competency development in business graduates: An industry-driven approach for examining the alignment of undergraduate business education with industry requirements," Int. J. Manag. Educ., vol. 10, no. 1, pp. 12-28, 2012.

[5] L. Vega Gónzalez, "La educación en ingeniería en el contexto global: propuesta para la formación de ingenieros en el primer cuarto del Siglo XXI," Ing. Investig. y Tecnol., vol. 14, no. 2, pp. 177190, 2013

[6] J. Cajide, J., Porto, A., Abeal, C., Barreiro, F., Zamora, E., Expósito, A., y Mosteiro, "Competencias adquiridas en la universidad y habilidades requeridas por los empresarios," Rev. Investig. Educ., vol. 20, no. 2, pp. 449-467, 2002.

[7] F. Minaya Rodriguez, Hojas Hojas, I. García del Toro Eva M., Pérez Chamizo,R. "Caja de Herramientas Formativas," in XVI Foro Internacional sobre Evaluación de la Calidad de la Educación Superior y la Investigación (FECIES), 2019, p. 100.

[8] I. Hojas Hojas, Minaya Rodriguez, F., García del Toro, Eva.M., Sánchez Lavín, J.R., Pérez Chamizo, R. "Buenas Prácticas en los Programas Formativos Orientados al Emprendimiento," in XV Foro Internacional sobre la Evaluación de la Calidad de la Investigación y la Educación Superior (FECIES)., 2018, p. 98.

[9] I. Hojas Hojas, Minaya Rodriguez, F., García del Toro, Eva. M., Sánchez Lavín, J. R., Pérez Chamizo,R. "Metodologías para el emprendimiento: Seguridad y Movilidad en las infraestructuras del siglo XXI," in Libro Resumenes XV FECIES, Santander, 2018, p. 98.

[10] Universidad Politécnica de Madrid, "ACTUA UPM," 2020. [Online]. Available: https://www.upm.es/ Investigacion/innovacion/CreacionEmpresas/Servicios/Competicion_Creacion_Empresas. [Accessed: 13-Jan-2020].

[11] European Commission, "HORIZON 2020 - WORK PROGRAMME 2014-2015 General Annexes Annex G . Technology readiness levels ( TRL )," no. 2014, p. 4995, 2014. 
[12] M. Serrano and P. Blázquez, Lidera el presente. Crea el futuro. Libros profesionales de empresa. 2015. 